\title{
Hybrid intelligent controller based torque ripple minimization in switched reluctance motor drive
}

\author{
V. Pushparajesh', B. M. Nandish ${ }^{2}$, H. B. Marulasiddappa ${ }^{3}$ \\ ${ }^{1}$ Department of Electrical and Electronic Engineering, Jain University, Bangalore, Karnataka, India \\ ${ }^{2,3}$ Department of Electrical and Electronic Engineering, JIT, VTU, Davanagere, Karnataka, India
}

\begin{tabular}{l} 
Article Info \\
\hline Article history: \\
Received Aug 16, 2020 \\
Revised Oct 12, 2020 \\
Accepted Apr 27, 2021 \\
\hline
\end{tabular}

Keywords:

Genetic neural network

Settling time

Speed response

Torque response

\begin{abstract}
An inherent torque ripple characterizes switched reluctance technology from conventional technology. The ultimate aim of this paper is to reduce the torque ripple of the switched reluctance motor drive using genetic neural network controller based direct torque scheme. In the proposed controller network appropriate bits of data are chosen for training and testing. The proper selection of the learning rate and momentum will help in weight adjustment. Here the error is reduced which proves that the selection of voltage vectors from the vector table is precise and its results in better torque response over a wide range of speed. The simulation results reveal that the torque ripples vary between $3.25 \%$ to $1.7 \%$ for the variation in load torque and the drive speed. The experimental results for the proposed controller reveal that the torque ripple varies between $3.7 \%$ to $2.1 \%$. Both the simulation and hardware results illustrate the efficiency of the controller.
\end{abstract}

This is an open access article under the CC BY-SA license.

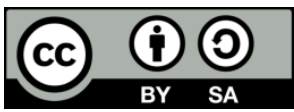

Corresponding Author:

V. Pushparajesh

Department of Electrical and Electronic Engineering

Jain University

Bangalore, Karnataka, India

Email: pushparajesh.v@gmail.com

\section{INTRODUCTION}

In the present scenario, the combination of robust and adaptive along with intelligent control appears to be the most important research accomplishment in the drive control area. The torque ripple along with the torque ripple is carried out by introducing direct instantaneous torque control [1]. The speed of the reluctance drive is regulated by using a novel adaptive TSK intelligent controller [2]. The inherent torque ripple characterizes is a widely reported issue not only in automotive and locomotive but also in biomedical systems such as optical coherence tomography (OCT) that makes use of galvanometer-based laser scanning systems [3]-[5]. The torque ripple in SRM drive is minimised by using artificial neural network based torque sharing function [6]. A high-performance control of SRM drive is achieved by using a common sharing method for current and flux-linkage [7]. The minimised torque ripple in the reluctance drive over a wide speed range is carried using torque sharing function [8]. The torque ripple in the SRM drive can be minimised by using fuzzy and adaptive neuro fuzzy inference system [9]. A meta-heuristic design of hysteresis current controller and fuzzy speed controller is used to mitigate the ripple in the torque in the reluctance motor drive [10]. The switched reluctance motor speed control along with the torque ripple minimization is achieved using non dominated sorting genetic algorithm [11]. A modified TSF with current compensation scheme is defined for high speed reluctance motor drive [12]. The noise and the ripple in the torque can be controlled using fuzzy excitation controller [13]. The reference torque is directly converted into reference current to reduce the ripple in the torque and copper loss in SRM drive [14]. A modified three level direct torque control (DTC) is 
used to overcome neutral point balance and vector switching [15]. Bridge converter and modified miller converter are used to minimise the torque ripple in SRM drive [16]. Destructive interference based torque ripple interference is used to eliminate torque ripple [17]. The least torque swell is achieved by differing the stator and rotor post grasp [18]. Fuzzly logic controller current compensation technique is used to reduce the torque ripples in SRM drives [19]. Fuzzy logic based DTC is used to control the speed and torque ripple of 8/6 SRM drive [20]. Sensorless speed control of 3 phase SRM drive is accomplished using ANFIS and fuzzy PID controller [21]. A modified TSF is discussed which is based on the linear function and non linear exponential function of the incoming and outgoing phases [22]. A neural network requires huge amount of data in the training process, so it takes large amount of time to gather data when the number of structural variables to be optimized is large [23]. In this paper the proposed controller is implemented by the integration of neural network with the DTC and optimized by using GA for SRM drive.

\section{GENETIC NEURO ON TORQUE RIPPLE REDUCTION}

The concept of GANN is the training of neural network by the genetic algorithm where we are going to improve the performance of the machine by means of reducing the torque ripple. Gravitational search algorithm schemes are using to control the speed of SRM along with torque ripple minimization [24]. Neural network has the inherent property of identification [25]. In this control the error torque is fed as the input to the neural network controller. Here in this paper the proposed neural network is trained by using supervised learning algorithm. A feed-forward back propagation neural network (BPNN) based DTC control along with GA is proposed in this research work to overcome the non-linearity in the characteristics, extensive ripples in the torque, better performance and cost sensitivity. By arranging the training data into several contiguous sets and developing a neural network controller with two-hidden-layer for the selection of the appropriate switching profile to minimise the torque ripple. Computed results reveals that the proposed control scheme minimise the ripples in the torque and improve the dynamic performance with the variation in the torque commands. The genetic algorithm used in this control scheme is to determine the weights and the threshold values in the network. The proper selection of population, crossover and mutation rate will determine the weight and the threshold value [26]. An optimization method that collaborates algorithm with limited component processing software takes a long time when there are so many structural variables to be optimized [27]. The reduced torque error along with flux error and sector is utilized to define the proper voltage vectors which is turn minimise the torque ripple.

\section{MODELING OF GENETIC NEURO CONTROLLER}

The proposed genetic neuro controller architecture shown in Figure 1 consist of one input layer, one output layer and two hidden layers. As the single hidden layer is not sufficient to determine the stability of the nonlinear system, two hidden layers are preferred. Output of the first hidden layer will be again added with the weight and is taken as the feedback to the next hidden layer. Output of these consecutive hidden layers is fed to the output layer after the summation of weights with the hidden layer data. The genetic algorithm is used to update the weights and the threshold values of the neural network.

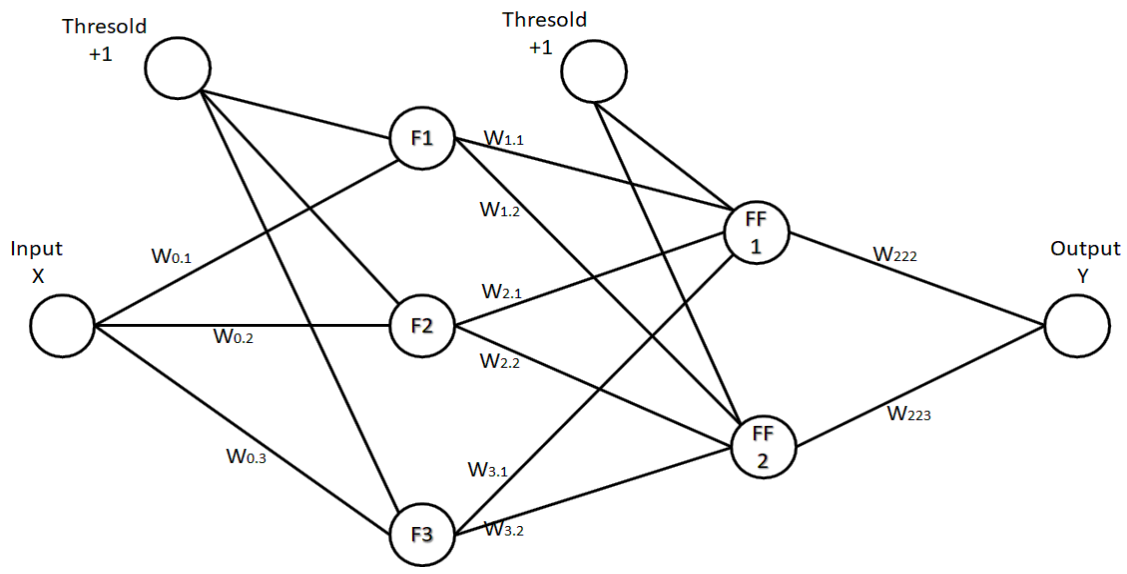

Figure 1. Architecture of the proposed network

The proposed controller is modelled with the population size of 50, crossover probability (c) is set as 0.8 , mutation rate (w) is set as 0.09 and the $\mathrm{R} 1$ and $\mathrm{R} 2$ are the variable used in the objective and fitness 
function. The number of data used for testing and training the network is selected as 100 . The learning rate is selected as 0.45 as the network structure is very simple in nature.

Initially, the bias is taken as 1 and the values are added along with the optimized weights which in turn reduce the torque error in the output. The gradient and the Mu value at the $11^{\text {th }}$ epoch is $1.214 \mathrm{e}-008$ and $1 \mathrm{e}-008$. Here the error is reduced at the early iteration which proves that the selection of voltage vector from the vector table is precise and it results in the reduction of torque ripple and less computation time. The threshold and the weight are normally represented as th and W. GA used for training the network is implemented by mentioning the maximum number of thresholds and weights which are packed in n-dimensional vector ' $M$ ' as shown by (1).

$$
\mathrm{M}=\left[\mathrm{th}_{1} \mathrm{w}_{01}, \mathrm{th}_{2} \mathrm{w}_{11} \ldots \ldots \ldots \ldots . . . \mathrm{th}_{16} \mathrm{~W}_{221}\right]=\left[\mathrm{m}_{1}, \mathrm{~m}_{2} \ldots . \mathrm{m}_{16}\right]
$$

\section{GENETIC NEURO BASED DIRECT TORQUE CONTROL}

DTC for AC drives was developed in the early ' 80 s where converter switching angle directly converts the motor variables, namely torque and flux. The reduction of ripples in the torque can be achieved by implementing a DTC technique with a novel lyapunov function [28]. The block diagram of the proposed controller based DTC is shown in Figure 2. The elimination of torque ripple is carried out by DTC and TSF method [29]. The ripples in the torque of the SRM drive can be eliminated by introducing a novel current profiling method [30]. A controller with lyapunov function is used to minimise the ripples in the torque of SRM drives [31]. The DTC reduced the ripples in the motor torque by regulating the motor torque within the hysteresis band [32]. In this proposed technique the actual flux and the torque are estimated from the stator voltage and the resistance. The reference torque is established from the speed error by the PI controller. The reference torque is compared with the actual torque that is measured and the resultant is fed as input to the proposed controller.

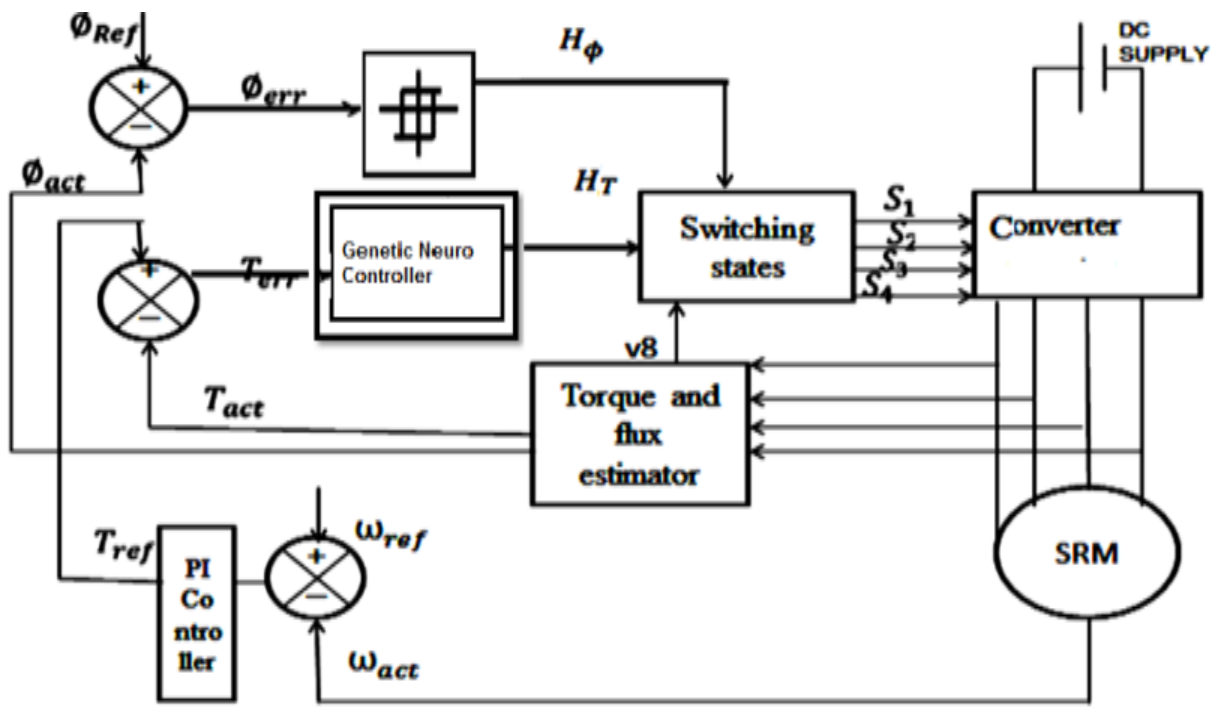

Figure 2. Block diagram of the proposed control system

The output from the genetic neuro controller is the reduced torque error. This error along with the flux and sector is used to select the actual voltage vectors from the lookup table. The selection of appropriate voltage vectors results in the proper sequence of turning on and off the power electronic converters resulting in proper excitation of the stator and the rotor poles [33]. The proper excitation between the aligned and unaligned inductance minimizes the torque ripple and also improve the motor performance both in static and dynamic condition.

\section{SIMULATION RESULTS}

The simulation is carried out in MATLAB/Simulink environment. A four-phase switched reluctance drive with the power output of $1.5 \mathrm{~kW}$ is considered for testing purpose. The aligned and unaligned inductances are made as $10 \mathrm{mH}$ and $49 \mathrm{mH}$ respectively. The rated speed of the drive is set as $3800 \mathrm{rpm}$, rated torque is calculated as $4 \mathrm{Nm}$ and the rated current $8 \mathrm{~A}$ /phase is considered for the drive. 


\subsection{Performance at rated load condition}

The drive is initially tested under the rated load condition by setting the reference speed as the rated one. The corresponding torque and current response are shown in Figure 3. The time scale difference between the phase current and torque is taken as 0.71-0.76 second is considered for measuring the responses. From the curve, it is observed that a maximum current of $8 \mathrm{~A}$ is reached during the rated condition.
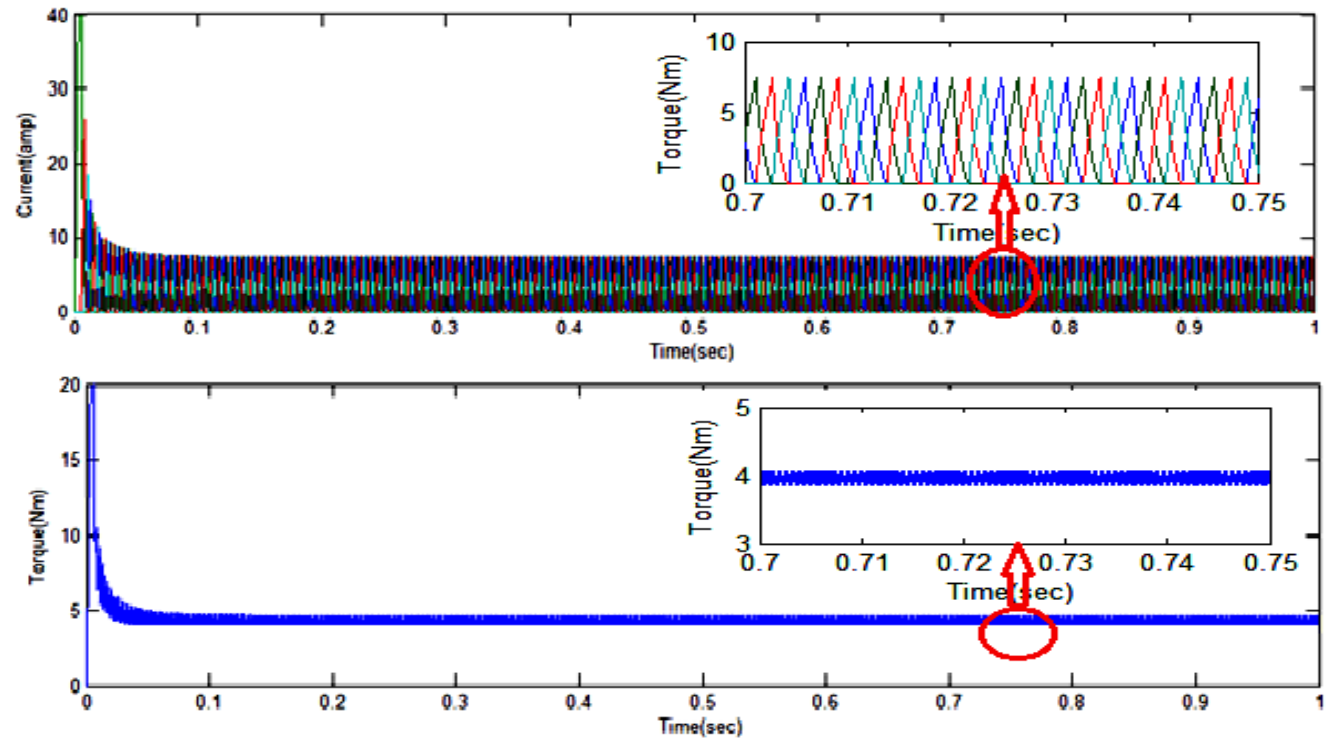

Figure 3. Current and torque response ate rated load condition

The torque error is minimized by the proposed controller which is shown in the above mentioned figure. The figure is further enlarged to specify the variation and accuracy of the ripples in the torque is shown in Figure 4. Figure 4(a) gives torque at rated speed, where as Figure 4(b) and 4(c) gives torque at half rated speed and $10 \%$ rated speed respectively.

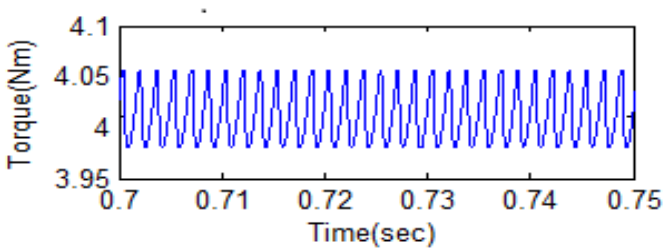

(a)

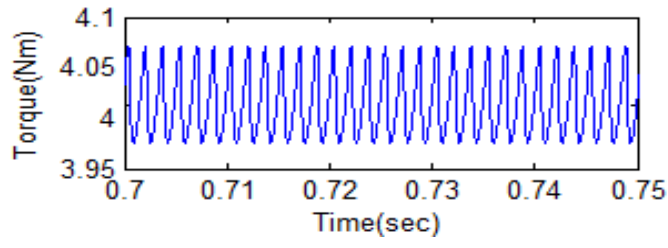

(b)

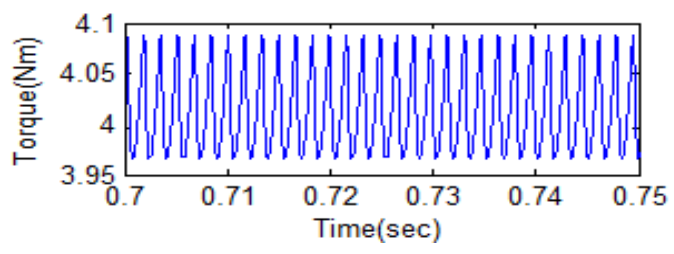

(c)

Figure 4. Torque ripple at rated torque, (a) rated speed, (b) half rated speed, (c) $10 \%$ of rated speed

\subsection{Performance at $75 \%$ of the rated torque condition}

The performance characteristics of the SRM drive are observed on the respective output terminals. The drive is tested with $75 \%$ of the rated load torque keeping the speed constant at the rated condition. The corresponding current and torque response are shown in Figure 5. From the curve, it is observed that maximum phase current of $6 \mathrm{~A}$ is reached during the specified condition. The above shown torque response curve is enlarged to show the accurate variation of torque under specified load condition with respect to wide variation of speed. The variation is observed and shown in Figure 6. Figure 6(a) gives torque at rated speed, where as Figure 6(b) and 6(c) gives torque at half rated speed and 10\% rated speed respectively. 

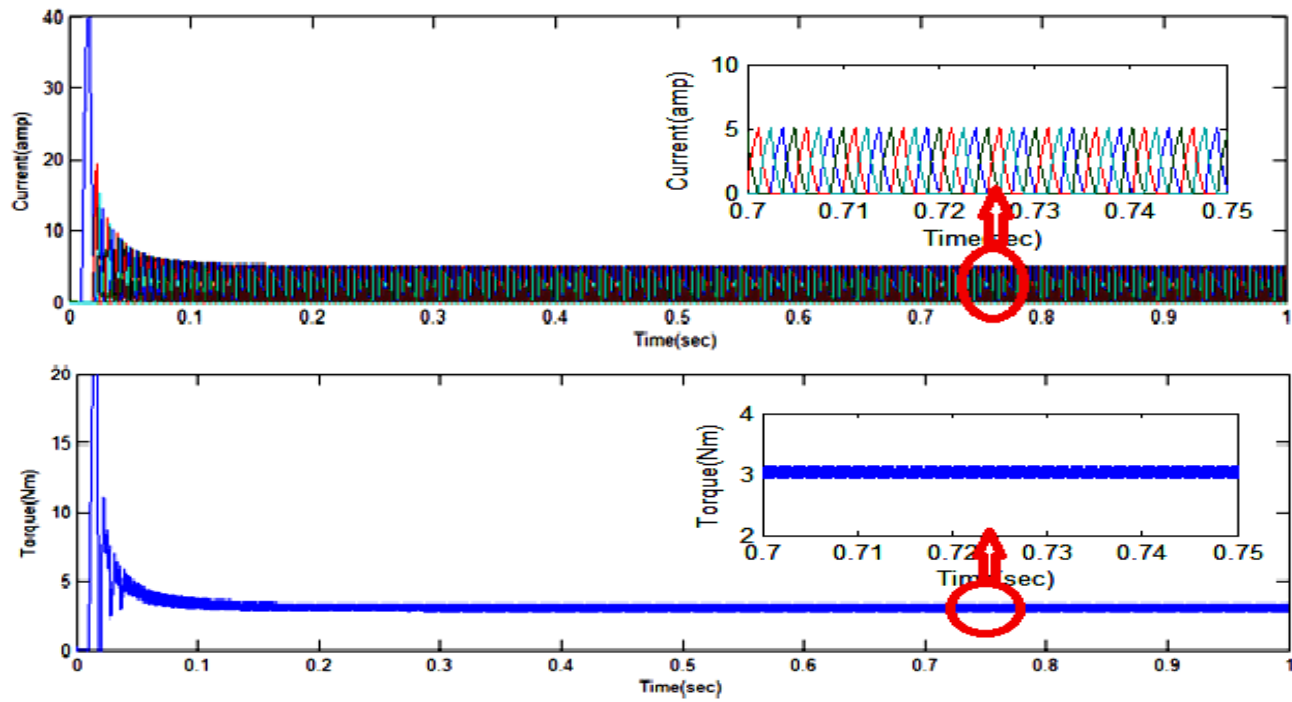

Figure 5. Phase current and torque response at $75 \%$ of the rated load with rated speed

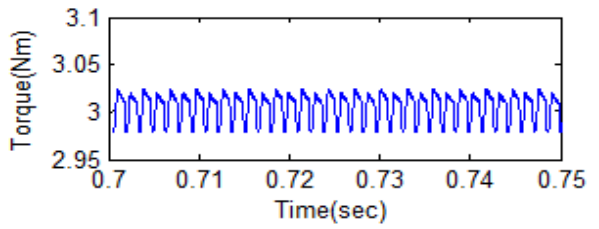

(a)

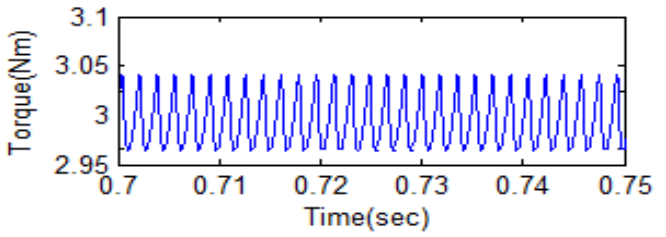

(b)

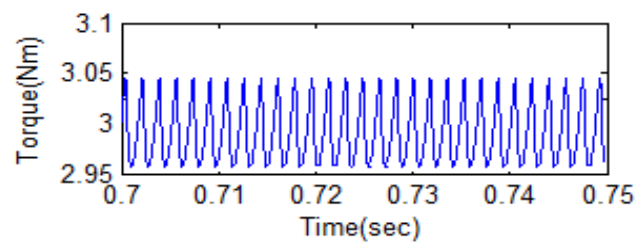

(c)

Figure 6. Torque response at $75 \%$ of the rated torque, (a) Rated speed, (b) Half rated speed, (c) $10 \%$ of rated speed

\subsection{Performance at $50 \%$ of the rated load torque}

The drive performance is observed on the respective scopes. The torque, speed and current response are observed and tabulated to know the effectiveness of the controller. The drive is simulated with $50 \%$ of the rated load condition keeping the speed at the rated condition. The corresponding torque and current response is shown in Figure 7. From the curve it is observed that maximum current of $3 \mathrm{~A}$ is reached during the rated condition. The torque response curve is enlarged to show the accurate variation of torque under specified rated load condition with respect to wide range of speed. The variation is observed and shown in Figure 8 . Figure 8(a) gives torque at rated speed, where as Figure $8(\mathrm{~b})$ and $8(\mathrm{c})$ gives torque at half rated speed and $10 \%$ rated speed respectively.

\subsection{Performance under dynamic load condition}

In the simulation carried out under dynamic condition, the speed was kept at rated condition and it is made constant. Two modes were considered in simulation as shown in Figure 9. At the starting mode, the command torque, $T_{\text {com }}$ was varied from $0 \mathrm{Nm}$ to $1 \mathrm{Nm}$ at $0.1 \mathrm{~s}$ and in the running mode, $T_{\text {com }}$ was varied from $1 \mathrm{Nm}$ to $2 \mathrm{Nm}$ at $0.5 \mathrm{~s}$. From the figure it shows that the drive performance under dynamic condition of the controller is quiet efficient. $T_{\text {out }}$ reaches to $2 \mathrm{Nm}$ at $0.03 \mathrm{~s}$. The high starting torque and current illustrate the motor capability over short duration loading ability. An analysis is made on the genetic neuro controller and the revealed observations are shown in Table 1. 

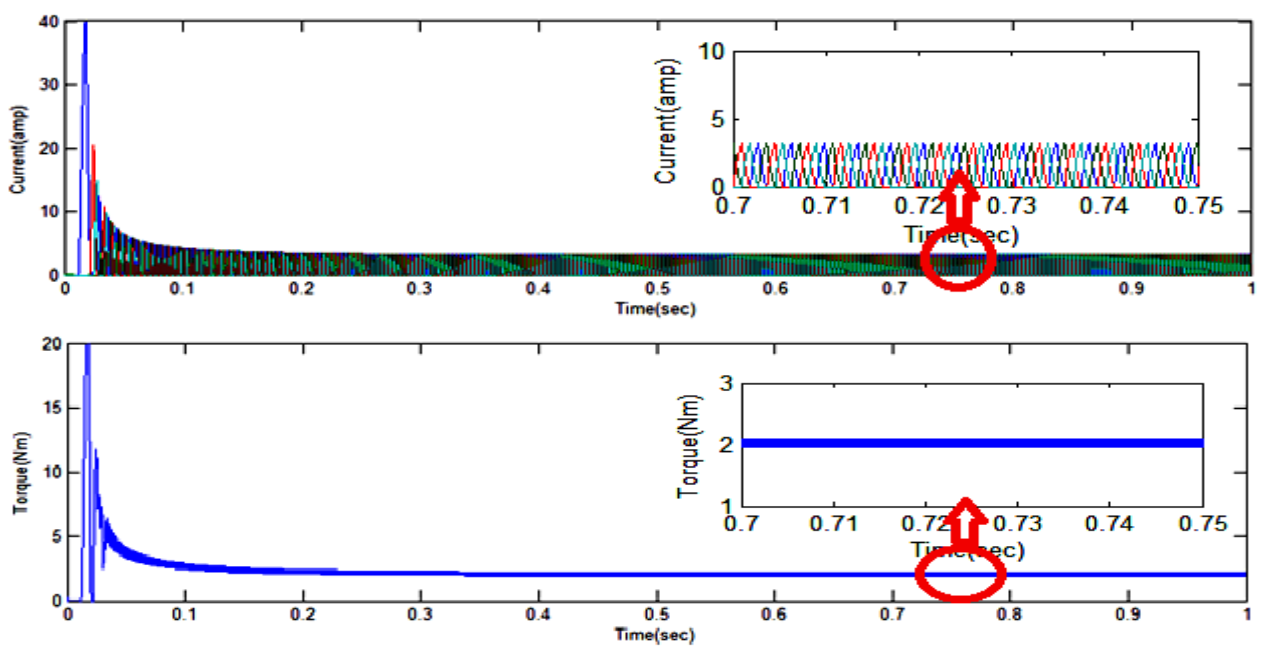

Figure 7. Current and torque response at $50 \%$ of the load torque with rated speed

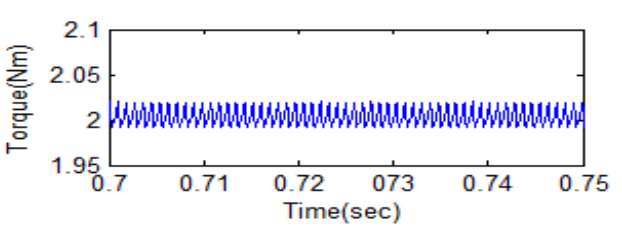

(a)

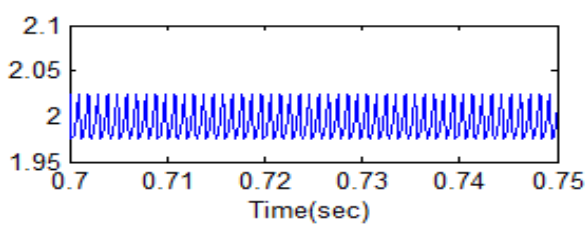

(b)

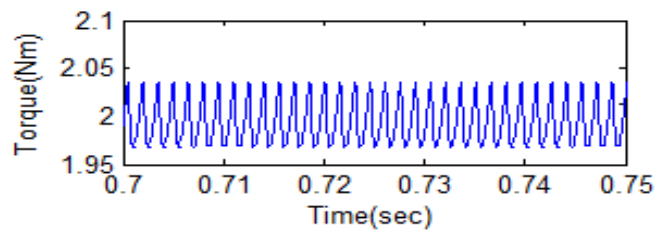

(c)

Figure 8 . Torque response at $50 \%$ of the rated torque, (a) rated speed, (b) half rated speed, (c) $10 \%$ of rated speed

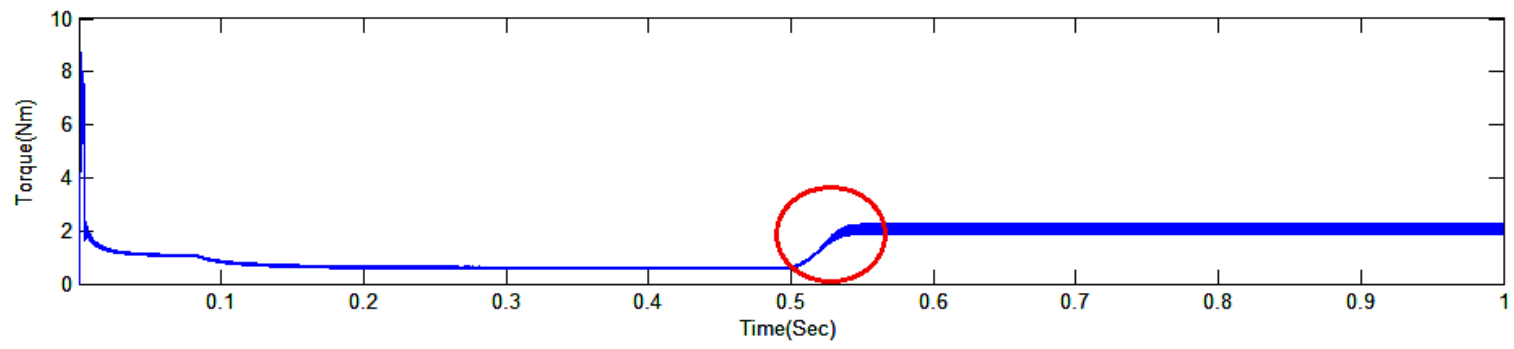

Figure 9. Torque profile under dynamic load condition

Table 1. Torque ripple at different load and speed conditions

\begin{tabular}{|c|c|c|c|c|c|c|}
\hline \multirow{2}{*}{ S.No } & \multirow{2}{*}{$\begin{array}{c}\text { Proposed Controller based } \\
\text { DTC }\end{array}$} & \multirow{2}{*}{$\begin{array}{l}\text { Rated Speed } \\
\text { in } \%\end{array}$} & \multicolumn{3}{|c|}{$\begin{array}{l}\text { Torque ripple in } \% \text { with respect to the } \% \text { Applied } \\
\text { load torque }\end{array}$} & \multirow{2}{*}{$\begin{array}{l}\text { Computational } \\
\text { Time }(\mathrm{sec})\end{array}$} \\
\hline & & & 100 & 75 & 50 & \\
\hline \multirow{3}{*}{1} & \multirow{3}{*}{ Genetic Neuro Controller } & 100 & 1.7 & 1.6 & 1.5 & \multirow{3}{*}{60} \\
\hline & & 50 & 2.5 & 2.3 & 2.2 & \\
\hline & & 10 & 3.25 & 2.9 & 2.48 & \\
\hline
\end{tabular}




\section{EXPERIMENTAL VERIFICATION AND RESULTS}

The proposed controller fed DTC is verified in a $1.5 \mathrm{~kW}, 8 / 6 \mathrm{SRM}$ drive shown in Figure 10. FPGA SPARTAN $3 \mathrm{~A} / 3 \mathrm{~A}$ is used to implement the genetic neuro controller and the experimental results are observed with the help of digital storage oscilloscope. In the experiment setup, flux reference is set as $0.3 \mathrm{~Wb}$ and the hysteresis bandwidth is fixed as 0.02 . The drive is driven by $\pm 120 \mathrm{~V} \mathrm{DC}$, rated speed of $3800 \mathrm{rpm}$, load torque of $4 \mathrm{Nm}$, aligned and unaligned inductance of $49 \mathrm{mH}$ and10 $\mathrm{mH}$ along with the inertia and friction is set as $0.08 \mathrm{~kg} . \mathrm{m} . \mathrm{m}$ and 0.01 N.m.s. The SRM drive is tested under different operating conditions both static and dynamic condition. The sampling time of the digital controller is set as $2 \mu \mathrm{s}$.

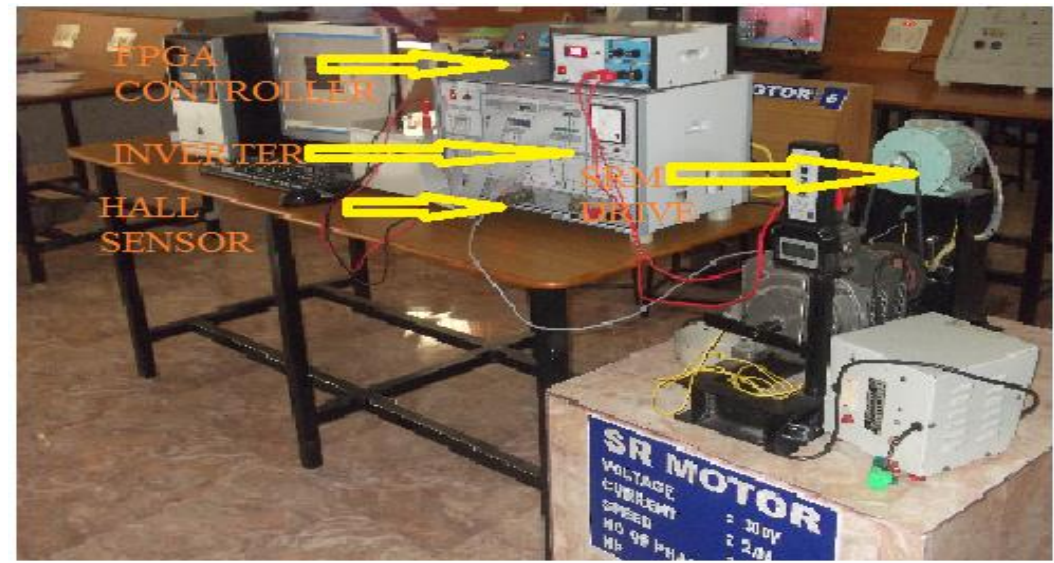

Figure 10. Experimental setup of SRM drive

\subsection{At rated load condition}

The proposed controller-based DTC fed switched reluctance motor is operated at various operating points in steady state conditions. Initially the motor rated torque is set at $4 \mathrm{Nm}$ and the rated speed is fixed at 3800rpm. Figure 11 shows the current for the four phases with the rated speed and the rated load torque. The current drawn by the SRM in experiment is $8 \mathrm{~A}$ which is equivalent to the current drawn in the simulation. Figure 11(a) gives torque at rated speed, where as Figure 11(b) gives torque at half rated speed.

\subsection{At variable load conditions}

The efficiency of the proposed controller is tested not only on the various operating speeds but also examined in various operating loads. The results are observed and tabulated to show the performance improvement of the proposed controller at various load torques. Initially the motor is loaded with $1 \mathrm{Nm}$ rated torque $(50 \%)$ as shown in Figure at various operating speed conditions. The test is further conducted for a load torque of half of the rated torque with the same operating conditions. The results are observed and shown in the Figure 12. Figure 12(a) gives torque at rated speed, where as Figure 12(b) gives torque at half rated speed.

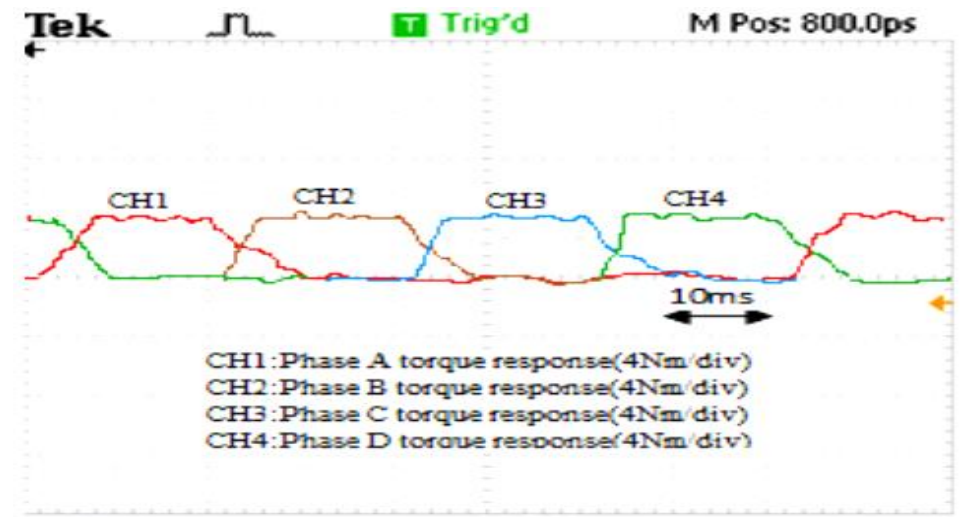

(a)

Figure 11. Torque response at rated load condition, (a) Rated speed 


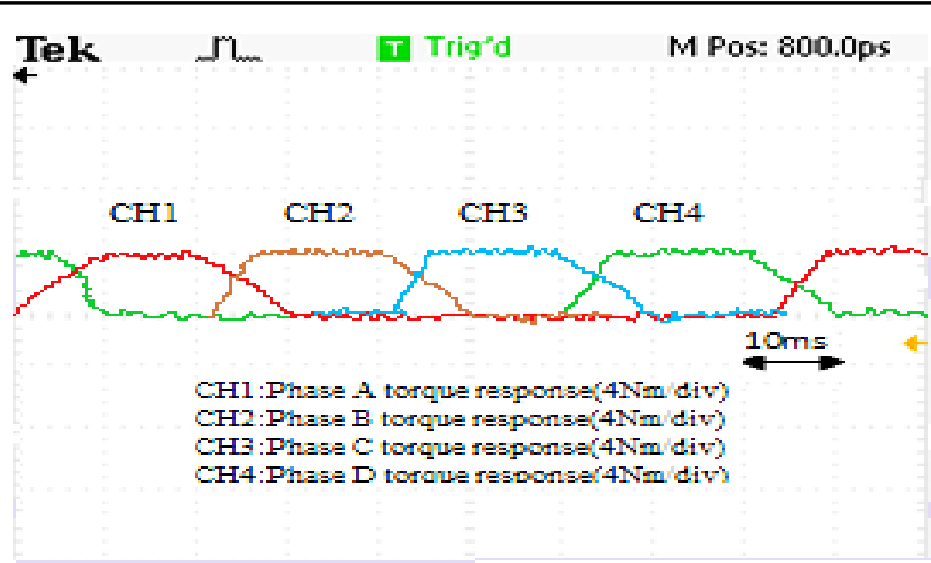

(b)

Figure 11. Torque response at rated load condition, (b) half Rated speed (continue)

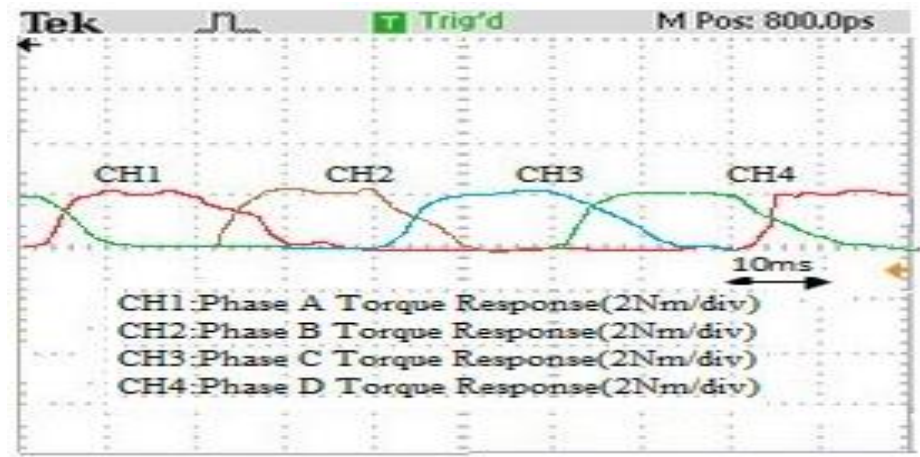

(a)

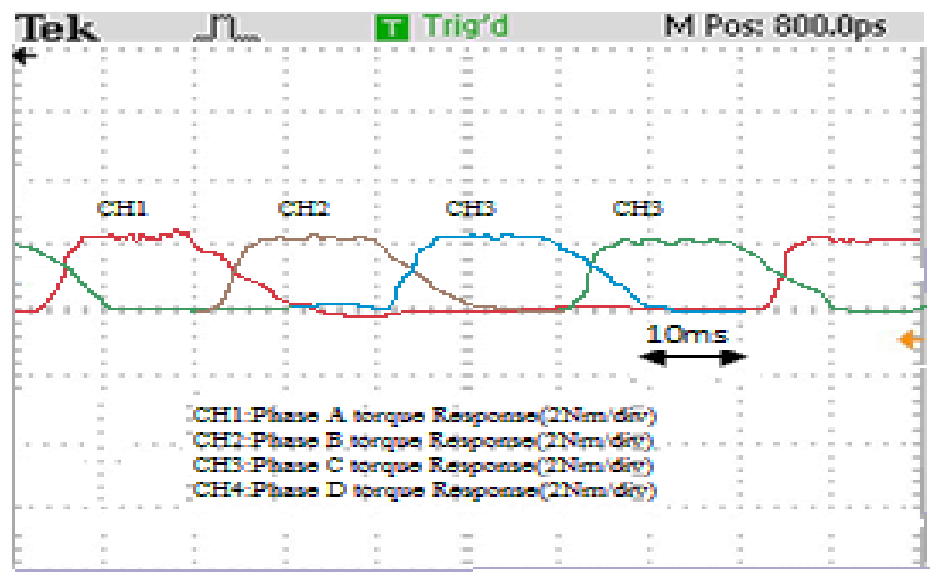

(b)

Figure 12. Torque response at half rated load, (a) Rated speed, (b) Half rated speed

The above measured torque ripple at different operating speed varies between $1.8 \%$ to $2.7 \%$. It is quite similar to the results reveled in the simulation where the torque ripple varies in the range of $1.5 \%$ to $2.48 \%$ for the same load torque and variable speed condition which proves the characteristics of the motor in real time. Similarly the drive is tested for $3 \mathrm{Nm}$ load torque with the same operating speeds. The results are measured at the specified rated load as shown in Figure 13. Figure 13(a) gives torque at rated speed, where as Figure 13(b) gives torque at half rated speed.

Are measured using textronics. The results show that the torque ripple measured in the experiment setup varies in the range of $2 \%$ to $3.1 \%$ which is similar to the results reveled in the simulation with respect to the torque ripple which varies in the range of $1.6 \%$ to $2.9 \%$. The results show that the reduction in torque ripple is quite improved in the proposed controller based DTC fed drive. The Table 2 shows the compartive 
results between the experimental setup and the simulation output at different operating points.

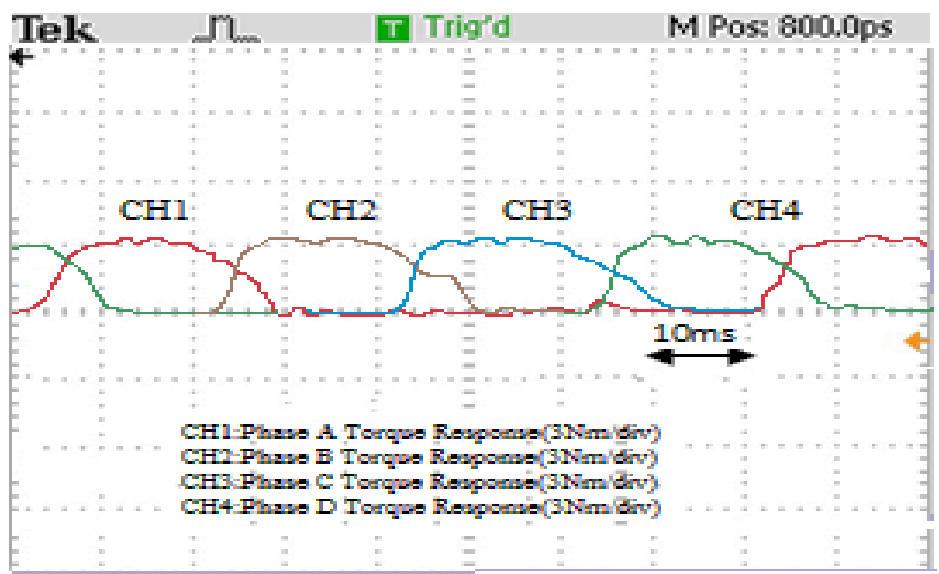

(a)

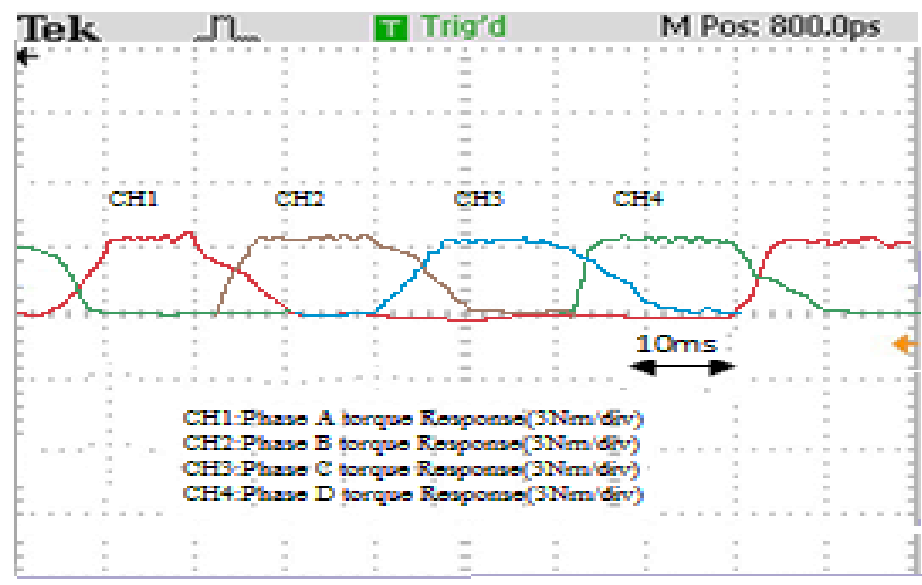

(b)

Figure 13. Torque response at 75\% rated load, (a) Rated speed, (b) Half rated speed

Table 2. Comparative analysis between simulation output and experimental results

\begin{tabular}{|c|c|c|c|c|c|c|}
\hline S.No & $\begin{array}{c}\text { Proposed } \\
\text { Controller based } \\
\text { DTC }\end{array}$ & $\begin{array}{c}\text { Rated Speed } \\
\text { in } \%\end{array}$ & \multicolumn{3}{|c|}{$\begin{array}{l}\text { Torque ripple in } \% \text { with respect to the } \% \text { applied } \\
\text { load torque }\end{array}$} & $\begin{array}{l}\text { Computational } \\
\text { Time(sec) }\end{array}$ \\
\hline 1 & Genetic Neuro & 100 & 1.7 & 1.6 & 1.5 & 6.60 \\
\hline \multirow{2}{*}{2} & Experimental & 100 & 2.1 & 2.0 & 1.8 & \multirow{2}{*}{10.40} \\
\hline & Results & 50 & 3.1 & 2.6 & 2.4 & \\
\hline
\end{tabular}

\section{CONCLUSION}

To overcome the drawback of torque ripple and speed response, GA-NN controller is proposed which will reduce the torque ripple below $2 \%$ over different operating conditions. The response of speed and torque is superior compared to the other conventional controller. Although the computational time is a little bit higher when compared to the overall performance, GA-NN seems to be the best to adopt with DTC for minimizing the torque ripple. The simulation and the experimental results clearly demonstrate that GA-NN based DTC for four phase SRM provides better performance in terms of reduced torque ripple, better speed and torque response both in steady state as well as in dynamic condition.

\section{REFERENCES}

[1] C. Labiod, K. Srairi, B. Mahdad, M. T. Benchouia, and M. E. H Benbouzid, "Speed control of 8/6 switched reluctance motor with torque ripple reduction taking into account magnetic saturation effects," Energy Procedia, vol. 74, pp. 112-121, 2015, doi: 10.1016/j.egypro.2015.07.530. 
[2] C. Tseng, S. Wang, S. Chien and C. Chang, "Development of a Self-Tuning TSK-Fuzzy Speed Control Strategy for Switched Reluctance Motor," in IEEE Transactions on Power Electronics, vol. 27, no. 4, pp. 2141-2152, April 2012, doi: 10.1109/TPEL.2011.2167244.

[3] R. K. Meleppat, M. V. Matham and L. K. Seah, "An efficient phase analysis-based wavenumber linearization scheme for swept source optical coherence tomography systems," Laser Physics Letters, vol. 12, no. 5, p. 055601, 2015, doi: 10.1088/1612-2011/12/5/055601.

[4] K. M. Ratheesh, L. K. Seah, and V. M. Murukeshan, "Spectral phase-based automatic calibration scheme for swept source-based optical coherence tomography systems," Physics in Medicine \& Biology, vol. 61, no. 21, p. 7652, 2016, doi: 10.1088/0031-9155/61/21/7652.

[5] R. K. Meleppat, M. V. Matham, and L. K. Seah, "Optical frequency domain imaging with a rapidly swept laser in the 1300nm bio-imaging window," in Proceedings of SPIE-The International Society for Optical Engineering (icOPEN 2015), Singapore, 2014, vol. 9524, doi: 10.1117/12.2190530.

[6] E. Gouda, M. Hamouda and A. R. A. Amin, "Artificial intelligence based torque ripple minimization of Switched Reluctance Motor drives," 2016 Eighteenth International Middle East Power Systems Conference (MEPCON), Cairo, Egypt, 2016, pp. 943-948, doi: 10.1109/MEPCON.2016.7837010.

[7] Jia-Jun Wang, "A common sharing method for current and flux-linkage control of switched reluctance motor," Electrical Power System Research, vol. 131, pp. 19-30, 2016, doi: 10.1016/j.epsr.2015.09.015.

[8] J. Ye, B. Bilgin and A. Emadi, "An Extended-Speed Low-Ripple Torque Control of Switched Reluctance Motor Drives," in IEEE Transactions on Power Electronics, vol. 30, no. 3, pp. 1457-1470, March 2015, doi: 10.1109/TPEL.2014.2316272.

[9] V. Pushparajesh and T. Manigandan, "Minimization of Torque Ripple in Direct Torque Controlled Switched Reluctance Drive Using Neural Network," Asian Journal of Research in Social Sciences and Humanities, vol. 6, no. 8, p. 65, 2016, doi: 10.5958/2249-7315.2016.00593.1.

[10] K. Lakshmanan, S. Perumal, and W. I. Mariasiluvairaj, "Artifical Intelligence-based control for torque ripple minimization in switched reluctance motor drives," Acta Scientrium Technology, vol. 36, no. 1, pp. 33-40, 2012, doi: 10.4025/actascitechnol.v36i1.18097.

[11] L. Kalaivani, P. Subburaj, and M. Willjuice Iruthayarajan, "Speed Control of switched reluctance motor with torque ripple reduction using non dominated sorting genetic algorithim," International Journal of Electrical power and Energy Systems, vol. 53, pp. 69-77, 2013, doi: 10.1016/j.ijepes.2013.04.005.

[12] J. Dee, S. Y. Ahn, and J. W. Ahn, "A simple negative torque compendation scheme for a high speed switched reluctance motor," Journal of Power Electronics, vol. 12, no. 1, pp. 58-66, 2012, doi: 10.6113/JPE.2012.12.1.58.

[13] S. Wang, F. Liu, C. Tseng, J. Chou, K. Lee and C. Lee, "Fuzzy Inference of Excitation Angle for Direct TorqueControlled Switched Reluctance Motor Drives," 2015 IEEE International Conference on Systems, Man, and Cybernetics, Hong Kong, China, 2015, pp. 1139-1144, doi: 10.1109/SMC.2015.204.

[14] V. P. Vujičić, "Minimization of Torque Ripple and Copper Losses in Switched Reluctance Drive," in IEEE Transactions on Power Electronics, vol. 27, no. 1, pp. 388-399, Jan. 2012, doi: 10.1109/TPEL.2011.2158447.

[15] Y. Zhang, J. Zhu, Z. Zhao, W. Xu and D. G. Dorrell, "An Improved Direct Torque Control for Three-Level Inverter-Fed Induction Motor Sensorless Drive," in IEEE Transactions on Power Electronics, vol. 27, no. 3, pp. 1502-1513, March 2012, doi: 10.1109/TPEL.2010.2043543.

[16] A. Ajan, J. Babu, M. Mohan, V. S. Nair and T. Babu, "Performance comparison of a bridge converter and a modified miller converter: Torque ripple minimization in switched reluctance motor," 2016 International Conference on Electrical, Electronics, and Optimization Techniques (ICEEOT), Chennai, India, 2016, pp. 35813584, doi: 10.1109/ICEEOT.2016.7755373.

[17] C. Laboid, K. Srairi, B. Mahdad, and M. E. H. Benbouzid, "A novel control technique for torque ripple minimization is switched reluctance motor through destructive interference," Electrical Engineering, vol. 100, pp. 481-490, 2017, doi: 10.1007/s00202-017-0521-7.

[18] A Veera Reddy and B Mahesh Kumar, "Torque Ripple minimization of Switched Reluctance Motor using Pole Embrace and Pole Configuration Methods," International Journal of Applied Engineering Research, vol. 13, no. 10, pp. 8525-8529. 2018.

[19] P. Pranay Kumar, "Torque ripple minimization of a Switched Reluctance Motor using Fuzzy logic control Current compensating technique," International Journal of Pure and Applied Mathematics, vol. 120, no. 6, pp. 587-598, 2018 .

[20] Hafeez ul Haq and Halil Ibrahim Okumus, "FLC-DTC method for torque ripples minimization of 8/6 switched reluctance motors drive," Journal of Advanced Research in Electrical Engineering, vol. 4, no. 1. pp. 51-55. 2020.

[21] L. Senthil Murugan and P. Maruthupandi, "Sensorless control of 6/4 pole switched reluctance motor using ANFIS and fuzzy-PID-based hybrid observer," Electrical Engineering, vol. 102, no. 6, pp. 831-844, 2020, doi: 10.1007/s00202-019-00915-5.

[22] Hady Abdel-Maksoud, "A Hybrid Torque Sharing Function with Controlled Commutation Period for Torque Ripple Minimization in SRM," International Journal of Intelligent Engineering and systems, vol. 13, no. 3, pp. 134-142, 2020, doi: 10.22266/ijies2020.0630.13.

[23] H. Sasaki and H. Igarashi, "Topology optimization of IPM motor with aid of deep learning," International Journal of Applied Electromagnetics and Mechanics, vol. 59, no. 1, pp. 87-96, Mar. 2019, doi: 10.3233/JAE-171164.

[24] Nutan shah and Sidhartha Panda, "Application of many optimizing liaisons technique for speed control with torque ripple minimization of switched reluctance motor," Asian Journal of convergance in technology, vol. 4, no. 2, pp. $1-10,2018$. 
[25] S. Ali, S. A. R. Kashif, H. Q. Ali and K. Toqueer, "Direct Torque Control of Inverter Fed Three Phase Induction Motor by Implementing Fuzzy Logic Controller," 2019 IEEE 6th International Conference on Engineering Technologies and Applied Sciences (ICETAS), Kuala Lumpur, Malaysia, 2019, pp. 1-8, doi: 10.1109/ICETAS48360.2019.9117481.

[26] N. Goel, R. N. Patel and S. Chacko, "Torque ripple reduction of DTC IM drive using artificial intelligence," 2016 International Conference on Electrical Power and Energy Systems (ICEPES), Bhopal, India, 2016, pp. 5-9, doi: 10.1109/ICEPES.2016.7915897.

[27] T. Song, Z. Zhang, H. Liu and W. Hu, "Multi-objective optimisation design and performance comparison of permanent magnet synchronous motor for EVs based on FEA," IET Electric Power Applications., vol. 13, no. 8, pp. 1157-1166, Aug. 2019, doi: 10.1049/iet-epa.2019.0069.

[28] P. Viswanathan and M. Thathan, "Hybrid Controller Based Instantaneous Torque Control of Four Phase Switched Reluctance Motor," Middle East Journal of Scientific Research, vol. 23, no. 11, pp. 2736-2747, 2015, doi: 10.5829/idosi.mejsr.2015.23.11.22765.

[29] Q. Sun, J. Wu, C. Gan, M. Shen and Y. Hu, "Investigation of direct torque control and torque sharing function strategy for switched reluctance motor applications," 2015 18th International Conference on Electrical Machines and Systems (ICEMS), Pattaya, Thailand, 2015, pp. 864-868, doi: 10.1109/ICEMS.2015.7385156.

[30] R. Mikail, I. Husain, Y. Sozer, M. S. Islam and T. Sebastian, "Torque-Ripple Minimization of Switched Reluctance Machines Through Current Profiling," in IEEE Transactions on Industry Applications, vol. 49, no. 3, pp. 12581267, May-June 2013, doi: 10.1109/TIA.2013.2252592.

[31] S. K. Sahoo, S. Dasgupta, S. K. Panda and J. Xu, "A Lyapunov Function-Based Robust Direct Torque Controller for a Switched Reluctance Motor Drive System," in IEEE Transactions on Power Electronics, vol. 27, no. 2, pp. 555-564, Feb. 2012, doi: 10.1109/TPEL.2011.2132740.

[32] S. Pratapgiri and P. P. V. Narsimha, "Direct torque control of 4 phase $8 / 6$ switched reluctance motor drive for constant torque load," World Journal of Modelling and Simulation, vol. 8, no. 3, pp. 185-195, 2012.

[33] M. Tarequzzaman, S. Ahmed and M. Moznuzzaman, "Performance Improvement of Direct Torque Control Induction Motor Drive using Genetic Algorithm Optimized PI Controller," 2018 International Conference on Advancement in Electrical and Electronic Engineering (ICAEEE), Gazipur, Bangladesh, 2018, pp. 1-4, doi: 10.1109/ICAEEE.2018.8642970.

\section{BIOGRAPHIES OF AUTHORS}

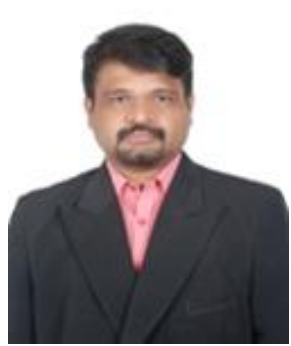

V. Pushparajesh has been serving as Associate Professor in the in the Department of Electrical and Electronics Engineering ,School of Engineering and Technology ,Jain Deemed to be University since 2017.He has completed his Ph.D from Anna University in Electrical Engioneeing specialised in Power Electronics and Special Electrical Drives and Master degree from Anna University specialized in Power Electronics and Drives.He also completed his Undergraduation from Bharathiar University in the stream of Electrical and Electronics Engineering. He is having a total experience of 15 years in the field of Academic and Research. He has received the International Best Research Award for the year 2018- 2019 instituted by SDF Internation, London, UK. Adding to his credit he also received national award like Best Academic Researcher, Outstanding faculty award, Best faculty award and Best Placement coordinator from various Research Organisation.He has published many papers in International and National journals with high Impact factor. He also presented many papers in National and International conferences. He has received a fund from AICTE worth of Rs.6,60,000/- for Power Electronics laboratory in MODROB Scheme in the Academic Year 2012-2013.He has received a Minor research project fund of Rs.60,000 from Jain Deemed to be University

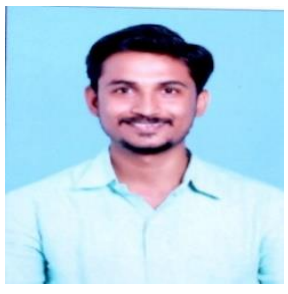

Nandish B M is currently a research fellow at Jain University, Kanakpura, Karnataka, India. He received his B.E. and M-Tech degree in Electrical and Electronics Engineering and Power systems in 2012 and 2014 respectively from VTU, Belagavi, karnataka, India. From March 2014 to August2020, he worked as Assistant Professor in the department of Electrical and Electronis Engineering at Jain Institute of Technology, Davanagere, Karnataka, India. His research include smart grid and IoT.

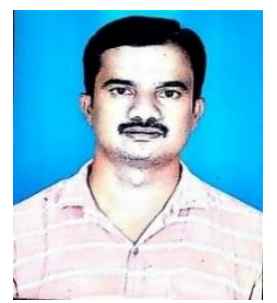

Marulasiddappa H Bis currently a research fellow at Jain University, Kanakpura, Karnataka, India. He received his B.E. and M-Tech degree in Electrical and Electronics Engineering and Power systems in 2005 and 2011 respectively from VTU, Belagavi, karnataka, India. From March 2015 to August2020, he worked as Assistant Professor in the department of Electrical and Electronis Engineering at Jain Institute of Technology, Davanagere, Karnataka, India. Area of Interest Power Electronics and Drives 